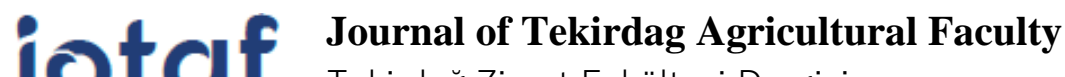 \\ Tekirdağ Ziraat Fakültesi Dergisi
}

Eylül/September 2019, 16(3)

Başvuru/Received: 22/05/19

Kabul/Accepted: 20/08/19

DOI: 10.33462 jotaf.568863

http://dergipark.gov.tr/jotaf

http://jotaf.nku.edu.tr/

ARAŞTIRMA MAKALESİ

RESEARCH ARTICLE

\section{Trakya Bölgesinde Buğday Üreticilerinin Tohumluk Tercihlerini Etkileyen Faktörlerin Analizi}

\author{
The Analysis Of Factors Affecting The Seed Choices Of Wheat Producers In The Trakya \\ Region
}

\section{$\ddot{\mathbf{O} z}$}

\section{Günay Keleş}

Bilindiği gibi yüksek kaliteli sert ya da yarı sert buğday çeşitlerinin verim düzeyi, yumuşak çeşitlere göre daha düşüktür. Türkiye'de yıllarca uygulanan fiyat politikaları, üreticileri yüksek verim arayışına itmiş ve düşük kaliteli buğday üretimi istemeden de olsa teşvik edilmiştir. Bu durum yüksek kaliteli buğdayın üretiminde istenilen düzeye ulaşılamamasına neden olmuştur. Un sanayicileri buğday piyasasında çok sayıda farklı çeşitle karşılaşmakta ve düşük kaliteli buğday bolluğu nedeniyle kaliteli un amacıyla oluşturulan üretim programları olumsuz yönde etkilenerek buğday ithalatı zorunlu olmaktadır. Bu süreç firıncıları ve nihai tüketicileri de olumsuz olarak etkilemektedir. Üreticilerin tohumluk tercihleri bu durum ile yakından ilgilidir. Faktör analizinin ana amacı boyut indirgemedir (dimension reduction). Boyut indirgemenin) amacı ise veri setini küçülterek daha kolay açıklanabilir hale getirmektir $\mathrm{Bu}$ araştırmanın amacı üreticilerin buğday tohumluğu tercihlerini etkileyen faktörleri belirleyerek çiftçi tercihlerini etkileyen faktörleri ‘Faktör Analizi’ yöntemi ile analiz etmektir. Böylece çok sayıda tercih nedeni daha düzenli bir şekilde tarım politikaları belirleyicileri ve uygulayıcılarına sunulabilmektedir. Analiz sonucunda elde edilen beş grup, buğday üreticilerinin tohumluk seçimine etki eden temel faktörleri göstermekte olup tecrübe ve tavsiye, yüksek Kalite ve Fiyat, İklim Koşullarına Uygunluk ve Destekleme Alımları olarak isimlendirilmiştir.

Anahtar Kelimeler: Faktör Analizi, Tohumluk, Üretici Tercihleri, Buğday, Trakya Bölgesi

\begin{abstract}
As is known, the yield level of high quality, hard or semi-hard, wheat varieties has lower yield level than soft varieties. Because of pricing policies applied in Turkey for many years, farmers have tend to the search for high yields and low quality wheat. It has been unintentionally promoted to production of soft varieties. This situation has caused the production of high quality wheat to undesired level. Flour industrialists are faced with many different varieties in the wheat market and due to the abundance of low-quality wheat, wheat production is mandatory due to the negatively affected production programs created for high-quality flour purposes. This process also affects the bakers and the consumers negatively. The seed preferences of the producers are closely related to this situation. The main purpose of factor analysis is dimension reduction. The aim is to make the data set easier to explain by reducing the data set. The purpose of this study is to determine the factors affecting the wheat seed preferences of the producers using factor analysis method. Thus, a large number of reasons for preference can be presented to agricultural policy makers and implementers more regularly. The five groups obtained as a result of the analysis as experience and advice, high quality and price, climate conditions compliance and support purchases.
\end{abstract}

Keywords: Factor Analysis, Seed, Farmer Preferences, Wheat, Thrace Region

\footnotetext{
1*Sorumlu Yazar/Corresponding Author: Gülay KELEŞ, Biyolojik Mücadele Araştırma Enstitüsü, 01321, Adana E-mail: gunaygungor99@gmail.com, (D) OrcID: 0000-0002-1634-724X.
}

Atıf/Citation: Keleş, G. Trakya Bölgesinde Buğday Üreticilerinin Tohumluk Tercihlerini Etkileyen Faktörlerin Analizi. Tekirdağ Ziraat Fakültesi Dergisi, 16(3), 423-431 


\section{Extendend Summary}

While the price policies implemented in our country for many years push the producers to seek high yields, it encourages the production of low quality wheat and it is seen that the desired level in the production of high quality wheat cannot be reached. Because the yield level of high quality hard or semi-hard wheat varieties is lower than low quality soft varieties. Flour industrialists are faced with many different varieties in the wheat market and due to the abundance of low-quality wheat, wheat production is mandatory due to the negatively affected production programs created for high-quality flour purposes. This process, experienced by flour industry, negatively affects the bakers and the consumers, which is the main food item. The seed preferences of the producers are closely related to this situation. The main purpose of factor analysis is dimension reduction. The aim is to make the data set easier to explain by reducing the data set. The purpose of this study is to determine the factors affecting the wheat seed preferences of the producers. Thus, it is possible to reach to some extent the information that will lead the determinants and implementers of agricultural policies by introducing a wide range of reasons. The five groups obtained as a result of the analysis as experience and advice, high quality and price, climate conditions compliance and support purchases.

Factor 1 defined as "Experience and Recommendation "; the experiences of the producers in the previous years (high yield) and the recommendations of various people and organizations play the most important role.

The second factor was defined as "High Quality and Price". This factor is related to market conditions.

The third factor identified as "Climatic Conditions Eligibility" was highly significant. Resistance to drought and cold is one of the important criteria that are frequently mentioned by Thrace farmers.

The fourth factor is defined in general such as Supporting Policies of government.

The last group is grouped under the heading Low Production Costs. 
Günümüzde tarım sektörünü bir taraftan korunup güçlendirilirken, diğer taraftan dünya ticaretindeki müdahaleler azaltılarak ticareti serbestleştirici önlemler üzerinde durulması yoluyla bir denge kurulmaya çalışılmaktadır. Bu gelişmeler birçok ülkede değişik tarımsal üretim kollarını farklı şekillerde etkilemekte ve hükümetleri gereken önlemleri almak ve düzenlemeleri yapmak zorunda bırakmaktadır. Zaman içerisinde bazı ürünlerde verilen destekler kesilirken, bazıları ise destekleme kapsamına alınmakta ve tarımdaki dengeler yerine oturtulmaya çalışılmaktadır.

Buğday üretimi, stratejik bir ürün olması nedeniyle tüm Dünyada çeşitli şekillerde desteklenmiştir. Ülkemizde ise bu anlamda daha çok fiyat ve girdi destekleme politikalarından yararlanılmıştır (Yılmaz vd.,1999). Özellikle toplum beslenmesinde temel gida hammaddelerini oluşturan ve çok geniş bir üretici kesiminin geçim kaynağı olan buğday için, üretim-işleme-tüketim süreci içerisindeki dengelerin yerine oturtulamadığı sıklıkla dile getirilmektedir. Ekmeklik, makarnalık ve bisküvilik buğday çeşitlerinin nitelik ve nicelik bakımından yetiştirilmesine son derece uygun olan ve farklı iklim bölgelerine sahip topraklarımızda, halen istenilen verim ve kalite düzeyine ulaşılamamıştır. Bu nedenle devlet, üretici, sanayici ve furıncılar ile nihai tüketiciler ilişkisinde sorunlar izlenmektedir.

Türkiye'de uygulanan fiyat destekleme politikaları, üreticileri yüksek verim arayışına iterken, düşük kaliteli buğday üretimini istemeden de olsa teşvik etmiş, yüksek kaliteli buğday üretiminde istenilen düzeye ulaşılamamıştır. Çünkü, yüksek kaliteli sert ya da yarı sert buğday çeşitlerinin verim düzeyi, düşük kaliteli yumuşak çeşitlere göre daha düşüktür. Un sanayicileri buğday piyasasında çok sayıda düşük kaliteli, farklı çeşitle karşılaşmakta ve kaliteli un üretim ve ihracat programları olumsuz yönde etkilenmektedir. Bu durum belirli buğday ithalatını zorunlu kılmaktadır. Un sanayicileri bir taraftan çeşit bolluğu ve kalite düşüklüğü sorunları ile karş1 karşıya iken; bir taraftan da sektörde çok sayıda fabrikanın tesis edilmesi ve kurulu kapasitenin oldukça yüksek tutulmasına bağlı olarak yoğun rekabetle; kayıt dışı ekonominin etkisiyle de haksız rekabetle mücadele etmek durumunda kalmaktadırlar (Güngör ve Güngör,2000). Un sanayinin yaşadığı olumsuz süreç halkın temel gıda maddesi olan ekmeği üreten firıncıları ve nihai tüketicileri de olumsuz olarak etkilemektedir. Bu araştırmanın amacı üreticilerin buğday tohumluğu tercihlerini etkileyen faktörleri belirleyerek çiftçi tercihlerini etkileyen faktörleri ‘Faktör Analizi' yöntemi ile analiz etmektir. Böylece çok sayıda tercih nedenlerini düzenli bir şekilde ortaya koyarak tarım politikaları belirleyicileri ve uygulayıcılarına bir ölçüde de olsa 1şı tutacak bilgilere ulaşmaktır.

\section{Materyal ve Yöntem}

Faktör analizi (FA), birbiriyle ilişkili çok sayıda değişkeni bir araya getirerek az sayıda kavramsal olarak anlamlı yeni değişkenler (faktörler, boyutlar) bulmayı keşfetmeyi amaçlayan çok değişkenli bir istatistik olarak tanımlanabilir (Büyüköztürk,2002). Başka bir deyişle, belirli sayıdaki bağımlı değişimin daha az sayıdaki bağımsız değiş̧kenler (veya faktörler) yardımıyla açıklanmasıdır (Yurdakul, 1974; Dağıstan, 2002). Faktör analizi, asıl amacı veri azaltma ve özetleme olan çok değişkenli istatistik metotların bir sınıfına verilen addır. Genel olarak, çok sayıda değişkenler arasında bulunan ilişkilerin analiz edilmesi ve daha sonra bu değişkenlerin genel esas boyutlar (faktörler) tarafından açıklanması problemine yöneliktir. Ayrıca, bu yöntemde her bir faktör orijinal gözlem değerlerinin bir fonksiyonu olan bağımlı bir değişken olarak da görülebilir (Joseph ve ark., 1992). İlk olarak 20.yüzyllin başlarında Spearman tarafından geliştirilen FA'nin yaygın kullanımı, bilgisayar teknolojisinde 1970'1i yıllarda yaşanan hızlı gelişme ile mümkün olabilmiş̧ir (Kline, 1994). Faktör analizinin ana amacı boyut indirgemedir (dimension reduction). Boyut indirgemenin en yaygın uygulaması olan keşfedici faktör analizinin (KFA) amacı ise veri setini küçülterek daha kolay açıklanabilir hale getirmektir (Brown, J. D., 2009).

Her değişken ve veri topluluğu faktör analizine uygun olmayabilir. Uygunluk koşulu için birçok test yapılmalıdır.

Bu kapsamda faktör analizi başlıca 4 aşamada yapılır (Çakır,2014).

1. Veri setinin faktör analizi için uygunluğunun değerlendirilmesi

2. Faktörlerin elde edilmesi,

3. Faktörlerin rotasyonu

4. Faktörlerin isimlendirilmesi aşamalarıdır. 
Verilerin, faktör analizi için uygunluğu Kaiser-Meyer-Olkin (KMO) katsayısı ve Barlett Sphericity testi ile incelenebilir. Örneklem korelasyonun güvenirliğini sağlayacak kadar büyük olmalıdır. Bunu belirlemek için Kaiser-Meyer-Olkin (KMO) testi yapılır. KMO'nun 1'e yaklaşan değer uygunluğu, 0.5'in altındaki değer kabul edilemez olduğunu gösterir. Barlett testinin ise $\mathbf{0 . 0 5}$ den küçük olması beklenir.

Faktörlerin elde edilmesi için öz değer (Eigen Value) hesaplanır. Bu değer hem faktörlerce açıklanan varyansı hesaplamada, hem de önemli faktör sayısına karar vermede dikkate alınan bir katsayıdır. Faktör analizinde, başlangıçta, genel olarak öz değeri 1 ya da 1'den daha büyük olan faktörler önemli faktörler olarak değerlendirilirler.

Faktörlerin rotasyonu aşamasında, Faktör yükleri matrisinin döndürülmesi daha yorumlanabilir bir faktör yapısının bulunmasına yardım eder. Maddeler döndürüldükten sonra varyans itibari ile daha optimal bir duruma gelirler. Analiz sonucunda önerilen 3 ise de, her faktörde kabul edilir en az 2 madde olmalı. Üst limit olmadığından ne kadar fazla madde, o kadar güvenilirlik ve açıklayabilirlik demektir. Son aşamada ise faktörlerin isimlendirilmektedir. Elde edilen sonuçlara göre maddelerin ağırlıklı olarak yığıldıkları faktörler dikkate alınarak, maddelerin ifade ettikleri anlama göre isimlendirme yapılır.

Araştırma sırasında öncelikle ankete tabi tutulacak kitlenin büyüklüğünü belirlemek için örnekleme yöntemi uygulanmış ve verilerin Faktör Analizine uygun olup olmadı̆̆ı tespit edilmiştir.

Ankete tabi tutulacak kitlenin büyüklüğünü saptamak için oluşturulan sonlu populasyona ilişkin parametreler aşağıda verilmiştir (Cochran, 1963) :

$\mathrm{N}=839$

$\mu=11982.13$ dekar (Yerleşim yeri başına düşen ortalama tarım arazisi)

$\sigma=10369.87$ dekar (populasyon standart sapmas1)

Örnekleme hatası (veya tahmin hatası) aritmetik ortalamanın $\mu \pm \% 10$ 'u kabul edilmiştir. Diğger bir ifadeyle çekilen örneğin aritmetik ortalaması populasyon oratamasından $\pm \% 10$ farklı olabilecektir. Diğer yandan, örnek ortalamasının bu sınır içerisine düşrne olasılığı \% 90 olarak kabul edilmiştir. Böylece, örnekleme hatası :

$(\mathrm{B})=\mathrm{Z}_{\mathrm{a} / 2} \cdot \sigma_{\mathrm{x}}$ veya $\mathrm{Z}_{\mathrm{a} / 2} . \sigma / V_{\mathrm{n}}$ olarak tanımlanmıştır. Örnek ortalamasına düşmesi beklenen aralık ise $\mu \pm \mathrm{Z}_{\mathrm{a} / 2}$. б/لn' dir.

Bu kabullere göre örnek hacmi,

$$
\begin{gathered}
{\left[\mathrm{Z}_{\mathrm{a} / 2} \cdot \sigma / \mathrm{B}\right]^{2}} \\
\mathrm{n}=\mathrm{-1}+\mathrm{N}\left[\mathrm{Z}_{\mathrm{a} / 2} \cdot \sigma / \mathrm{B}\right]^{2}
\end{gathered}
$$

164 yerleşim yeri, illere optimum olarak dağıtılmış ve illerde 10.000 dekar ve daha yüksek buğday ekim alanına sahip olan köyler öncelikli olarak tercih edilmiştir. Köylerin seçiminde Tarım İl ve İlçe Müdürlükleri kayıtlarına göre 10.000 dekar ve daha fazla buğday ekim alanına sahip olan köyler gayeli olarak tercih edilmiştir; üretici tercihlerini belirleyebilmek için her yerleşim yerinden 5 adet çiftçi ile görüşülmesi ve böylece 164 yerleşim yerinde toplam 820 anket yapılması planlanmıştır. Bununla beraber un sanayicilerinin talebi nedeniyle bilgi alınması gereken 9 köy daha belirlenmiş ve bu köylerin ziyaretleri ile toplam köy sayısı 173 adede ulaşmıştır. Buna göre gidilmesi gereken köy ve uygulanması gereken anket sayısı aşağıdaki şekilde oluşturulmuştur. 
Çizelge 1. Uygulanan anket sayısı

Table 1.Number of survey

\begin{tabular}{lccc}
\hline \multicolumn{1}{c}{ İller } & Köy Sayısı & Anket Sayısı & \% \\
\hline Edirne & 34 & 170 & 19,7 \\
\hline Tekirdağ & 57 & 285 & 32,9 \\
\hline Kırklareli & 42 & 210 & 24,3 \\
\hline İstanbul & 31 & 155 & 17,9 \\
\hline Çanakkale & 9 & 45 & 5,2 \\
\hline Toplam & $\mathbf{1 7 3}$ & $\mathbf{8 6 5}$ & $\mathbf{1 0 0 , 0}$ \\
\hline
\end{tabular}

\section{Bulgular ve Tartışma}

Üreticilerin tohum seçimini etkileyen faktörleri değerlendirmek amaciyla faktör analizi uygulanmıştır. Faktör analizi tarım ekonomisi araştırmalarında daha önce Yurdakul (1973), Aksoy ve Ark. (1997) ve Konyalı ve Gaytancıoğlu (2007), Dağıstan ve Ark.(2007), Yılmaz (2010) ile pek çok bilim insanı tarafından kullanılmış ve son derece tutarlı sonuçlara ulaşılabilmiştir.

Çizelge 2. Faktörlerin elde edilmesi

Table 2.Determination of factors

\begin{tabular}{|c|c|c|c|c|c|c|}
\hline & Tercih Nedenleri & 1.Faktör & 2.Faktör & 3.Faktör & 4. Faktör & 5. Faktör \\
\hline 1 & Yüksek verimli olması & 0,615 & $-0,707$ & , & $-0,222$ & $-0,268$ \\
\hline 2 & Komşu üreticinin etkisi ve tavsiyesi & $\mathbf{0 , 5 2 3}$ & $-0,732$ & 0,408 & , & $-0,156$ \\
\hline 3 & Tarım kredi koop. tavsiyesi & 0,924 & 0,375 & , & , & , \\
\hline 4 & Büyük üreticinin etkisi ve tavsiyesi & 0,946 & 0,263 & , & $-0,165$ & , \\
\hline 5 & Önder çiftçilerin tavsiyesi & $\mathbf{0 , 9 4 7}$ & , & $-0,167$ & $-0,159$ & $-0,206$ \\
\hline 6 & İl/İlçe Müdürlüğünün tavsiyesi & $\mathbf{0 , 8 9 3}$ & 0,365 & , & $-0,183$ & 0,188 \\
\hline 13 & Kök çürüklüğüne dayanıklı olması & 0,744 & , & 0,323 & 0,102 & 0,570 \\
\hline 18 & Erkenci bir çeşit olması & 0,904 & $-0,356$ & , & 0,210 & 0,108 \\
\hline 7 & Sanayicilerin istediği çeşit olması & , & 0,768 & 0,629 & , & , \\
\hline 8 & Sanayicilerin yüksek fiyat vermesi & 0,144 & $\mathbf{0 , 8 7 8}$ & 0,428 & 0,109 & $-0,118$ \\
\hline 9 & Tüccarın istediği çeşit olması & 0,220 & $\mathbf{0 , 9 2 7}$ & 0,271 & 0,128 & , \\
\hline 10 & Tüccarın daha yüksek fiyat vermesi & $-0,233$ & $\mathbf{0 , 8 0 1}$ & 0,533 & $-0,128$ & , \\
\hline 14 & Toprak yapısına daha uygun olması & $-0,818$ & 0,355 & $-0,301$ & $-0,322$ & 0,104 \\
\hline 15 & Kalitesinin yüksek olması & 0,200 & 0,964 & , & , & 0,151 \\
\hline
\end{tabular}




\begin{tabular}{|c|c|c|c|c|c|c|}
\hline 17 & İstikrarlı ve tanınan çeşit olması & , & 0,712 & 0,210 & 0,665 & , \\
\hline 21 & Yatmama özelliği olması & 0,257 & 0,428 & $-0,857$ & 0,115 & , \\
\hline 22 & Başka tohum bulunamaması & $-0,448$ & $\mathbf{0 , 3 1 0}$ & $-0,799$ & 0,202 & 0,153 \\
\hline 11 & Soğuğa dayanıklı olması & $-0,635$ & $-0,115$ & 0,729 & 0,197 & 0,112 \\
\hline 12 & Kurağa dayanıklı olması & $-0,843$ & , & 0,474 & $-0,149$ & $-0,186$ \\
\hline 16 & TMO'nun her çeşit buğdayı alması & , & $-0,868$ & , & 0,318 & $-0,363$ \\
\hline 20 & Hayvan yemi olarak kullanılabilmesi & , & $-0,659$ & 0,257 & $\mathbf{0 , 5 4 0}$ & 0,455 \\
\hline 19 & Samanı bol olduğu için üretilmesi & $-0,297$ & $-0,454$ & 0,432 & $-0,527$ & 0,490 \\
\hline 23 & Daha az gübre gereksinimi & $-0,455$ & 0,223 & $-0,828$ & , & 0,237 \\
\hline
\end{tabular}

$\mathrm{Bu}$ araştırmada da analiz yapılmadan önce mevcut verilerin faktör analizine uygun olup olmadığı test edilmiştir. Bu amaçla uygulanan KMO (Kaiser-Mayer-Olkin) testi oldukça uygun $(0,669)$ bulunmuştur.

Faktör ile kriter arasındaki bağımlılık oranı yüzde birden daha düşük ise değer yazılmamış, sadece bir nokta konmuş ve böylece bağımlılığın önemsenmeyecek kadar az olduğu ifade edilmek istenmiştir (Yurdakul, 1973).

Çizelge 2'de verilen 23 farklı kriter ile ilgili değerlere faktör analizi uygulandığında "eigenvalue" değerleri 1 'den büyük olan beş faktör grubu elde edilmektedir (Çizelge 3). Bu beş faktör grubunun toplam varyansın \%100'ünü açıkladığı çizelgede görülmektedir.

Buna göre 1. grupta $(1,2,3,4,5,6,13,18), 2$. grupta $(7,8,9,10,14,15,17,21,22), 3$. grupta (11 ve 12), 4.grupta (16 ve 20) ile 5. grupta 19 ve 23) no'lu değişkenler toplanmaktadır. Elde edilen beş grup, buğday üreticilerinin tohumluk seçimine etki eden temel faktörleri göstermekte olup son derece uygun ve anlamlı çıkmıştır.

Faktör analizinde en güç aşamalardan birisi faktörlerin "isimlendirilmesi”dir. Ancak analiz sonucu beklenmedik düzeyde uygun faktörleri bir araya getirmiş ve her bir grubu tanımlayabilecek bir başlık kolaylıkla belirlenebilmiştir (çizelge 4). Faktörler aşağıdaki başlıklar altında gruplandırılmıştır:

- Tecrübe ve Tavsiye

- Yüksek Kalite ve Fiyat

- İklim Koşullarına Uygunluk

- Destekleme Alımları

- Düşük Üretim Maliyeti

Çizelge 3. Sonuç istatistiği

Table 3. Result statistics

\begin{tabular}{cccc}
\hline Faktörler & $\begin{array}{c}\text { Aynı Kökenlilik Değeri } \\
\text { (Eigen Value) }\end{array}$ & Varyans (\%) & $\begin{array}{c}\text { Kümülatif } \\
\text { Varyans }\end{array}$ \\
\hline Faktör 1 & 7,982 & 34,706 & 34,706 \\
\hline Faktör 2 & 7,687 & 33,422 & 68,128 \\
\hline Faktör 3 & 4,462 & 19,399 & 87,527 \\
\hline Faktör 4 & 1,281 & 6,876 & 94,403 \\
\hline Faktör 5 & 1,287 & 5,597 & 100,000 \\
\hline
\end{tabular}

“Tecrübe ve Tavsiye" olarak tanımlanan 1. Faktör içerisine; üreticilerin daha önceki yıllarda ekmiş oldukları tohumluk performanslarına göre edindikleri tecrübeler (yüksek verim) ile çeşitli kişi ve kuruluşların tavsiyeleri önemli bir rol oynamaktadır. En güçlü etkilenme kriterinin de bu faktör olduğu çizelgelerde belirlenen yüksek 
oranlardan da anlaşılabilmektedir. İkinci faktör "Yüksek Kalite ve Fiyat" olarak tanımlanmıştır. Nitekim un sanayicileri ve tüccarların istediği çeşitler olması ve daha yüksek fiyat verilmesi gibi kriterlerin bu grupta öncelikli olarak yer alması nedeniyle uygun bir başlık olarak düşünülmüştür.

“İklim Koşullarına Uygunluk” olarak belirlenen üçüncü faktör son derece anlamlı çıkmıştır. Kurağa ve soğuğa dayanıklılık Trakya Üreticisi tarafından sıklıkla dile getirilen tercih kriterleri arasındadır.

Dördüncü faktör "Destekleme Alımları" gibi genel bir ifade ile tanımlanmıştır. Düşük kaliteli ancak yüksek verimli tohumluk seçiminde kararlı olan üreticiler, bunun nedenini “TMO’nun her çeşit buğdayı kalitesine bakmaksızın aynı fiyattan alması" şeklinde ifade etmektedirler. Bunun yanısıra, "Hayvan yemi olarak da kullanılabilmesi" kriteri, düşük kalite olgusunu destekler nitelikte olup; uygun grupta yer aldığı izlenimi vermektedir. Son grup ise "Düşük Üretim Maliyeti” başlığı ile gruplandırılmıştır.

Çizelge 4. Faktörlerin İsimlendirilmesi

Table 4. Name of Factors

\begin{tabular}{|c|c|c|c|c|}
\hline $\begin{array}{l}\text { Tecrübe ve } \\
\text { Tavsiye }\end{array}$ & $\begin{array}{c}\text { Yüksek Kalite ve } \\
\text { Fiyat }\end{array}$ & $\begin{array}{c}\text { İklim } \\
\text { Koşullarına } \\
\text { Uygunluk }\end{array}$ & $\begin{array}{c}\text { Destekleme } \\
\text { Alımları }\end{array}$ & $\begin{array}{l}\text { Düşük Üretim } \\
\text { Maliyeti }\end{array}$ \\
\hline (1. Faktör) & (2. Faktör) & (3. Faktör) & (4. Faktör) & (5. Faktör) \\
\hline $\begin{array}{l}\text { Yüksek verimli } \\
\text { olması }\end{array}$ & $\begin{array}{l}\text { Sanayicilerin istediği } \\
\text { çeşit olması }\end{array}$ & $\begin{array}{l}\text { Soğuğa dayanıklı } \\
\text { olması }\end{array}$ & $\begin{array}{l}\text { TMO'nun her çeşit } \\
\text { buğdayı alması }\end{array}$ & $\begin{array}{l}\text { Samanı bol olduğu } \\
\text { için üretilmesi }\end{array}$ \\
\hline $\begin{array}{l}\text { Komşu üreticinin } \\
\text { etkisi ve tavsiyesi }\end{array}$ & $\begin{array}{l}\text { Sanayicilerin yüksek } \\
\text { fiyat vermesi }\end{array}$ & $\begin{array}{l}\text { Kurağa dayanıklı } \\
\text { olması }\end{array}$ & $\begin{array}{l}\text { Hayvan yemi olarak } \\
\text { kullanilabilmesi }\end{array}$ & $\begin{array}{l}\text { Daha az gübre } \\
\text { gereksinimi }\end{array}$ \\
\hline $\begin{array}{l}\text { Tarım kredi koop. } \\
\text { tavsiyesi }\end{array}$ & $\begin{array}{l}\text { Tüccarın istediği çeşit } \\
\text { olması }\end{array}$ & & & \\
\hline $\begin{array}{l}\text { Büyük üreticinin } \\
\text { etkisi ve tavsiyesi }\end{array}$ & $\begin{array}{l}\text { Tüccarın daha yüksek } \\
\text { fiyat vermesi }\end{array}$ & & & \\
\hline $\begin{array}{l}\text { Önder çiftçilerin } \\
\text { tavsiyesi }\end{array}$ & $\begin{array}{l}\text { Toprak yapısına daha } \\
\text { uygun olması }\end{array}$ & & & \\
\hline $\begin{array}{l}\text { İl/İlçe } \\
\text { Müdürlüğünün } \\
\text { tavsiyesi }\end{array}$ & $\begin{array}{l}\text { Kalitesinin yüksek } \\
\text { olması }\end{array}$ & & & \\
\hline $\begin{array}{l}\text { Kök çürüklüğüne } \\
\text { dayanıklı olması }\end{array}$ & $\begin{array}{l}\text { İstikrarlı ve tanınan çeşit } \\
\text { olması }\end{array}$ & & & \\
\hline \multirow[t]{2}{*}{$\begin{array}{l}\text { Erkenci bir çeşit } \\
\text { olması }\end{array}$} & $\begin{array}{l}\text { Yatmama özelliği } \\
\text { olması }\end{array}$ & & & \\
\hline & $\begin{array}{l}\text { Başka tohum } \\
\text { bulunamaması }\end{array}$ & & & \\
\hline
\end{tabular}

\section{Sonuç}

Trakya Bölgesindeki buğday üreticilerinin tohumluk seçimini etkileyen faktörlerin analiz edilmesi sonucunda, çiftçilerin en çok önem verdiği kriterlerin sırasıyla, tecrübe ve tavsiye, yüksek kalite ve fiyat, iklim koşullarına uygunluk, destekleme alımları ve düşük üretim maliyetleri olduğu belirlenmiştir. Çiftçilerin yıllar boyunca edindikleri kendi tecrübeleri ile komşu üreticilerin, büyük çiftçilerin, önder çiftçilerin, Tarın İl/İlçe müdürlüğü elemanlarının ve tarımsal kooperatiflerin tavsiyelerinin tohum seçimini etkileyen en önemli faktörler olduğu anlaşılmaktadır. Sonuçlar incelendiğinde; çiftçilerin tercihlerini etkileyen en önemli ikinci faktör ise piyasa koşulları ile ilgili çeşitli unsurları içermektedir. Çiftçiler, tüccar ve un sanayicilerinin talepleri doğrultusunda kalite ve fiyatı gözeterek de ekecekleri buğday çeşidinin seçimine karar vermektedirler. O halde fiyat politikaları belirlenirken bu durumun göz önüne alınması oldukça olumlu sonuçlar sağlayabilecektir. gibi Sanayicilerin ihtiyacı olan çeşitlerin üretiminin teşvik edilmesi, ithal edilecek buğday miktarını minimum düzeye düşürebilecektir. Diğer taraftan kaliteli un üretimi un ihracatında avantaj sağlayabilecektir. Üçüncü faktör iklim 
koşullarına dayanıklılık olup, bu faktörün üçüncü sırada gelmesi yöreye özgü çeşitlerin önemli ölçüde belirlendiğini de göstermektedir.

Destekleme alımları dördüncü faktör olarak bulunmuştur. TMO'nun alışılagelmiş politikası nedeniyle ortaya çıkan bu faktör, sadece TMO fiyatlarına göre hareket eden önemli bir üretici kitlesinin olduğunu da göstermektedir. Düşük üretim maliyetlerinin dördüncü sırada çıkması piyasada oluşabilecek fiyatın daha önemli olduğunun da bir göstergesi sayılabilir. Çiftçilere göre fiyat yeterince yüksek olursa maliyetlerin karşılanması sorun olmaktan çıkmaktadır. Sonuç olarak; tarım sektörüne yönelik yapılan araştırmalarda faktör analizi yöntemi ile yüzlerce bilgi, belirli başlıklar altında toplanabilir, çok daha anlaşılır ve kolay yorumlanabilir hale getirilebilir. Uygulanacak politikaların işlerliği, aynı zamanda kaynak israfını azaltarak sektördeki sorunların azalmasını sağlayabilecektir. 


\section{Kaynakça/References}

Aksoy, Ş.,Azabağaoğlu, Ö., Unakıtan, G., Gaytancıoğlu O., Özdemir, G., (1997), Türkiye Bitkisel Yağ Raporu, Bitkisel Yağ Sanayicileri Derneği Yayınları no:3

Brown, J. D. (2009). Statistics Corner Questions and answers about language testing statistics: Principal components analysis and exploratory factor analysis, In.Definitions, differences, and choices, Shiken: JALT Testing and Evaluation SIG Newsletter, 13(1),26-30.

Büyüköztürk, Ş., Faktör Analizi: Temel Kavramlar Ve Ölçek Gelistirmede Kullanimi, Kuram Ve Uygulamada Egitim Yönetimi Dergisi, Güz 2002, Sayi: 32 Ss.470-48, Ankara.

Cochran, W.C., 1963. Sampling Techniques, 2nd ed., A Wiley International Edition

Çakır, A., 2014, Faktör Analizi, İstanbul Ticaret Üniversitesi Sosyal Bilimler Enstitüsü, Doktora Tezi, No.1250D91213, İstanbul, S.4-8.

Dağıstan, E., Koç, B., Gül, A., Gül, M., 2008. Koyunculuk Üretim Faaliyetinin Faktör Analizi: Orta-Güney Anadolu Örneği. Yüzüncü Yıl Üniversitesi, Ziraat Fakültesi, Tarım Bilimleri Dergisi, 18 (2): s. 67-77, Van.

Güngör, H., Güngör, G., 2001, “Trakya Bölgesi Un Sanayi Sektör Analizi”, T.Ü. Araştırma Fonu Projesi, TÜAF-301, Edirne.

Joseph, F., Hair, Jr,. Rolph, E.A., Ronald, L.T. William, C.B., 1992. Multivariate Data Analysis. Macmillan Publishing Company. A division of Macmillan, Inc. Third Edition. New York, U.S.A. pp.239.

Kline, P. (1994). An Easy Guide To Factor Analysis:. New York: Routledge. Nunnally, J. (1978). Psychometric Theory (Second edition). New York: McGraw HilL.

S. Konyalı O. Gaytancıoğlu, 2007, Türkiye'de Buğdayda Uygulanan Tarım Politikaları ve Trakya Bölgesi Buğday Üreticilerinin Sorunları, Tekirdağ Ziraat Fakültesi Dergisi Cilt 4, Sayı 3, Sayfalar 249 - 259, Tekirdağ.

Stapleton, C. D. (1997). Basic concepts and procedures of confirmatory factor analysis. Annual Meeting of the Southwest Educational Research Association, Austin, 23-25 Ocak 1997. 12 Haziran 2017 tarihinde http://files.eric.ed.gov/fulltext/ED407416.pdf adresinden erişilmiştir.

Yaşlığlu, M., M., 2017, Sosyal Bilimlerde Faktör Analizi ve Geçerlilik: Keşfedici ve Doğrulayıcı Faktör Analizlerinin Kullanılması, Istanbul University Journal of the School of Business İstanbul Üniversitesi İşletme Fakültesi Dergisi Vol/Cilt: 46, Special Issue/Özel Sayı 2017, 74-85 ISSN: 1303-1732.

Yılmaz, H., 2010, Süt Siğirciliğinda Kooperatifler Araciliğiyla Desteklemenin Ekonomik Ve Sosyal Etkileri: Adana İli Örneği, Ç.Ü.Fen Bilimleri Enstitüsü, Doktora Tezi, Adana.

Yurdakul, O., 1973 'Tarım İşletmelerinde Yeni Bir Metod 'Faktöriyel Analiz’,Ç.Ü.Ziraat Fakülti Dergisi, Cilt:4, Sayı:11 ve 12, Adana. 